\title{
Novas ocorrências de Briófitas para Pernambuco, Brasil
}

\author{
Lisi Dámaris Pereira Alvarenga ${ }^{1,2}$, Mércia Patrícia Pereira Silva ${ }^{1}$, \\ Juliana Rosa do Pará Marques de Oliveira ${ }^{1}$ e Kátia Cavalcanti Pôrto ${ }^{1}$
}

Recebido em 12/06/2006. Aceito em 20/10/2006

\begin{abstract}
RESUMO - (Novas ocorrências de briófitas para Pernambuco, Brasil). Levantamentos da flora de briófitas em duas áreas remanescentes de Floresta Atlântica, a Reserva Ecológica (RE) Gurjaú (08¹0'00'S e 3502'30'O; 50-150 m n.a.m.) e a Reserva Particular de Patrimônio Natural (RPPN) Frei Caneca (0842'37'’S e 3550'01'”O; 500-750 m n.a.m.), resultaram no registro de 15 novas ocorrências para o Estado de Pernambuco. São elas 11 hepáticas das famílias Cephaloziaceae, Jubulaceae, Herbertaceae, Lejeuneaceae, Lepidoziaceae, Metzgeriaceae e quatro musgos das famílias Calymperaceae, Pterobryaceae, Sematophyllaceae e Thuidiaceae. Sete destas espécies são também novas referências para a região Nordeste. As espécies são ilustradas e comentadas quanto aos caracteres taxonômicos mais relevantes.
\end{abstract}

Palavras-chave: Hepáticas, musgos, Floresta Atlântica, Pernambuco

\begin{abstract}
New occurrences of Bryophytes to Pernambuco, Brazil). Floristic surveys of Bryophytes in Atlantic Rain Forest

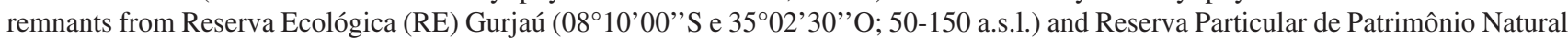
(RPPN) Frei Caneca (08 $42^{\prime} 37^{\prime \prime} S$ e 35 50'01'O; 500-750 a.s.1.), registered 15 new ocurrences to Pernambuco State. They are 11 liverworts of Cephaloziaceae, Jubulaceae, Geocalycaceae, Herbertaceae, Lejeuneaceae, Lepidoziaceae, Metzgeriaceae and four mosses of Calymperaceae, Pterobryaceae, Sematophyllaceae and Thuidiaceae. Seven of these species are new references for Northeastern area of Brazil. The species are illustrated and commented about relevant taxonomic characters.
\end{abstract}

Key words: Liverworts, Mosses, Atlantic forest, Pernambuco

\section{Introdução}

O Estado de Pernambuco possui $98.281 \mathrm{~km}^{2}$ de extensão territorial e apresenta grande variedade de tipos vegetacionais inseridos nos ecossistemas de Formações Litorâneas, Floresta Atlântica e Caatinga (Tabarelli \& Silva 2002). As briófitas são referidas para todos os ecossistemas do Estado, todavia, são nos remanescentes de Floresta Atlântica e "Brejos de Altitude", que estas plantas são encontradas em maior abundância e diversidade (Pôrto 1990; Germano \& Pôrto 1996; Pôrto et al. 1999; 2000; Pôrto \& Germano 2002).

Os primeiros registros de briófitas para Pernambuco datam do século XIX (Pôrto 1996), contudo foi apenas após 1980 que as coletas e os trabalhos científicos sistemáticos foram intensificados, tornando o Estado um dos mais bem inventariados da região Nordeste (Pôrto 1990; Pôrto \& Germano 2002). Listagens e compilações da literatura apontam para uma riqueza total de briófitas de mais de 300 espécies, ca. $10 \%$ do que é referido no país (Yano 1995). Contudo, estudos recentes realizados em remanescentes de Floresta Atlântica revelam que ainda há uma riqueza desconhecida (Germano \& Pôrto 2004; 2005). De fato, as listagens resultantes dos últimos inventários ratificam esta asserção e o presente trabalho relata o registro de 15 táxons referidos pela primeira vez para o Estado, alguns dos quais apresentam ocorrência geográfica ou ecológica restrita.

\section{Material e métodos}

Os táxons aqui apresentados provêm de levantamentos realizados em duas Unidades de Conservação de Floresta Atlântica ao norte do rio São Francisco: a Reserva Ecológica (RE) Gurjaú (08 $10^{\circ} 00^{\prime}$ 'S e $\left.35^{\circ} 02^{\prime} 30^{\prime \prime} \mathrm{O}\right)$ e a Reserva Particular de Patrimônio Natural (RPPN) Frei Caneca (842’37's

\footnotetext{
1 Universidade Federal de Pernambuco, Departamento de Botânica, Laboratório Biologia de Briófitas, CCB, Av. Prof. Moraes Rêgo s/n, Cidade Universitária, 50670-901 Recife, PE, Brasil

2 Autora para correspondência: lisidamaris@yahoo.com.br
} 
e 3550'01'O), em Pernambuco.

As áreas em que estas unidades estão inseridas possuem clima Tropical Quente com distinção apenas entre estação seca e chuvosa (Andrade \& Lins 1984; Siqueira Filho \& Leme 2000). A RE Gurjaú localiza-se na região costeira do Estado, possui altitude de 50 a 150 m e é classificada como Floresta Ombrófila Densa de Terras Baixas (Veloso et al. 1991). As médias anuais de temperatura e precipitação pluviométrica são $25{ }^{\circ} \mathrm{C}$ e $2.301 \mathrm{~mm}$, respectivamente, e o relevo é ondulado (Andrade \& Lins 1984). A RPPN Frei Caneca possui altitude de 500 a $750 \mathrm{~m}$ e é classificada como Floresta Ombrófila Densa Submontana (Veloso et al. 1991), tem médias anuais de temperatura e precipitação pluviométrica de $23{ }^{\circ} \mathrm{C}$ e $1.305 \mathrm{~mm}$, respectivamente, e relevo montanhoso acidentado (Siqueira Filho \& Leme 2000).

O material botânico estudado consistiu em amostras de briófitas epífitas, epífilas e epíxilas e foi identificado até o nível específico com base, principalmente, nos trabalhos de Sharp et al. (1994), Buck (1998) e Gradstein \& Costa (2003) e, quando necessário, confirmado por especialistas. O sistema de classificação usado seguiu Crandall-Stotler \& Stotler (2000) para Marchantiophyta e Goffinet \& Buck (2004) para Bryophyta. O material testemunho encontra-se depositado no Herbário UFP - Geraldo Mariz, da Universidade Federal de Pernambuco.

Todas as novas ocorrências são apresentadas em ordem alfabética de família e ilustradas enfatizando os caracteres de valor taxonômico. São fornecidos, ainda, comentários de relevância taxonômica e notas ecológicas, além da distribuição geográfica mundial e no Brasil. Para isso foram consultados os catálogos de Yano $(1981 ; 1984 ; 1989 ; 1995 ; 2006)$ e os trabalhos de Fulford (1963; 1966), Bischler (1969), Stotler (1970), van Reenen (1982), Kron (1988), Costa \& Machado (1992), Allen (1993), Pôrto et al. (1993), Reese (1993), Sharp et al. (1994), Harley (1995), Lisboa \& Lima (1997), Buck (1998), Bernecker-Lücking (1998), Gradstein et al. (2001), Dauphin (2003), Gradstein \& Costa (2003), Câmara \& Vital (2004), Visnadi (2004), Yano (2004), Yano \& Câmara (2004), Câmara \& Leite (2005), Câmara et al. (2005), Costa et al. (2005), Valente \& Pôrto (2006) e Yano \& Pôrto (2006).

\section{Resultados e discussão}

Das 15 espécies de briófitas apresentadas, 11 pertencem à Divisão Marchantiophyta e quatro à Divisão Bryophyta. Os táxons estão distribuídos em
10 famílias: seis famílias de hepáticas, Cephaloziaceae, Herbertaceae, Jubulaceae, Lejeuneaceae, Lepidoziaceae, Metzgeriaceae, e quatro de musgos, Calymperaceae, Pterobryaceae, Sematophyllaceae e Thuidiaceae. Dentre estas famílias, seis pertencem às 15 listadas por Gradstein \& Pócs (1989) como detentoras de $90 \%$ da diversidade de briófitas de Florestas Tropicais Úmidas.

\section{MARCHANTIOPHYTA}

\section{CEPHALOZIACEAE}

1. Odontoschisma denudatum (Nees) Dumort., Recueil Observ. Jungerm.: 19. 1835.

Fig. 1-6

Material examinado: BRASIL. Pernambuco: Município de Jaqueira, RPPN Frei Caneca, Serra do Quengo, 31/X/2003, sobre tronco morto, K.C. Pôrto (UFP 37961).

Descrição: Fulford (1966).

Comentários: caracteriza-se por apresentar ramos flageliformes com gemas e ápices avermelhados; filídios ovalados a redondo-ovalados, usualmente côncavos; células com paredes espessadas e trigônios conspícuos. Geralmente encontrada em florestas montanas sobre troncos caídos, húmus ou rochas, entre 500-1.500 m de altitude. Distribuição geográfica: América Tropical, América do Norte e Europa. Distribuição no Brasil: AM, BA, RJ, SC e SP.

\section{HERBERTACEAE}

2. Herbertus juniperoideus (Sw.) Grolle, Rev. Bryol. Lichénol. 30: 80. 1961.

Fig. 7-11

Material examinado: BRASIL. Pernambuco: Município de Jaqueira, RPPN Frei Caneca, Serra do Quengo, 25/III/2003, sobre tronco morto, K.C. Pôrto (UFP 37960).

Descrição: Fulford (1963) e van Reenen (1982).

Comentários: caracteriza-se pelo gametófito robusto, filídios mais ou menos assimétricos até duas vezes mais longos que largos, com vita ocupando 1/ 5 a 3/4 da largura da base e terminando próximo ou no ápice, bifurcada logo abaixo do sinus e anfigastro simétrico. Geralmente encontrada como epífita e saxícola, ao longo de rios de florestas úmidas que apresentam neblina constante, entre 2.200-2.300 m de altitude. Distribuição geográfica: Neotropical. Distribuição no Brasil: Estados de BA, CE, ES e RJ. 


\section{JUBULACEAE}

3. Frullania breuteliana Gottsche, Syn. Hep: 461. 1844.

Fig. 12-16

Material examinado: BRASIL. Pernambuco: Município de Jaqueira, RPPN Frei Caneca, Serra do Quengo, 30/X/2003, sobre tronco vivo, L.D.P. Alvarenga (UFP 40813; UFP 50927); ibid. 30/X/2003, sobre folha, L.D.P. Alvarenga (UFP 50893); ibid. 31/X/2003, sobre folha, L.D.P. Alvarenga (UFP 50889).

\section{Descrição: Stotler (1970).}

Comentários: pertence ao subgênero Frullania Raddi e caracteriza-se pelos filídios assimetricamente ovalados, com ápice acuminado e anfigastros bífidos, alongados a oblongo-ovalados, ca. 1,5 a 2 vezes mais largos que o caulídio. Espécie semelhante a Frullania beyrinchiana (Lehm. \& Lindenb.) Lehm. \& Lindenb., porém $F$. breuteliana tem filídios conspicuamente acuminados, margem dorsal inteira a crenulada e brácteas e bractéolas denteadas. Geralmente encontrada como epífita e epífila no interior da mata, entre 0-2.250 m de altitude. Distribuição geográfica: Neotropical. Distribuição no Brasil: RJ, RS e SP. Novo registro para o Nordeste.

4. Frullania involuta Hampe ex Steph., Sp. Hepat. 4: 595. 1911.

Fig. 17-22

Material examinado: BRASIL. Pernambuco: Município de Jaqueira, RPPN Frei Caneca, Serra do Quengo, 25/III/2003, sobre tronco morto, K.C. Pôrto (UFP 37968).

Descrição: Kron (1988).

Comentários: pertence ao subgênero Meteoriopsis Spruce e caracteriza-se por apresentar filídios côncavos, auriculados, aplexos ao caulídio mesmo quando úmidos; ápice acuminado e margem sinuosa a distintamente serreada; anfigastros com lobos acuminados e células medianas com paredes sinuosas. Geralmente encontrada como epífita em florestas úmidas que apresentam neblina constante, entre 0-2.250 m de altitude. Distribuição geográfica: Neotropical. Distribuição no Brasil: CE, RJ e SP.

\section{LEJEUNEACEAE}

5. Ceratolejeunea confusa R.M. Schust., J. Elisha Mitchell Sci. Soc. 72: 310. 1956.

Fig. 23-30
Material examinado: BRASIL. Pernambuco: Município Cabo de Santo Agostinho, RE de Gurjaú, Mata do Café 25/VIII/2003, sobre tronco vivo, L.D.P. Alvarenga (UFP 50981); ibid. 25/VIII/2003, sobre tronco vivo, L.D.P. Alvarenga (UFP 40805); RPPN Frei Caneca, município de Jaqueira, Mata do Xangô 25/VIII/2003, sobre tronco vivo, L.D.P. Alvarenga (UFP 50955); Serra do Quengo 30/X/2003, sobre tronco vivo, L.D.P. Alvarenga (UFP 50960).

Descrição: Dauphin (2003).

Comentários: caracteriza-se pelos filídios com 1 a 3 ocelos basais, anfigastros orbiculares, grandes, 160-312 $\mu \mathrm{m}$ de largura, e perianto com cinco quilhas, sem cornos, utrículos ocasionais e simples, lóbulos esféricos ausentes e lobos dos fílídios sempre inteiros. É similar a C. cornuta (Lindenb.) Schiffn., sendo que esta apresenta perianto com 4 cornos bem desenvolvidos e lóbulos esféricos ocasionais. Geralmente encontrada sobre troncos de árvores no dossel, em áreas abertas a ca. 200 m. Distribuição geográfica: Neotropical. Distribuição no Brasil: AM, PA e SP. Novo registro para o Nordeste.

6. Ceratolejeunea minuta Dauphin, Flora Neotropica, monograph 90: 66. 2003.

Fig. 31-35

Material examinado: BRASIL. Pernambuco: Município Cabo de Santo Agostinho RE de Gurjaú, Mata do Cuxio 7/II/2003, sobre tronco vivo, L.D.P. Alvarenga (UFP 51009); ibid. 7/II/2003, sobre tronco vivo, L.D.P. Alavarenga (UFP 38195).

Descrição: Dauphin (2003).

Comentários: espécie de pequeno porte, com gametófitos de 0,4 a 0,6 mm de largura, que se caracteriza pelos anfigastros pequenos, 50-100 $\times 95-145 \mu \mathrm{m}$, com um dente na margem lateral e sinus em "U", sendo que este último caráter não foi freqüente nos espécimes observados, os quais apresentaram tanto sinus em "U" como em "V". Geralmente encontrada como epífita e epífila em florestas úmidas de terras baixas, entre $0-800 \mathrm{~m}$ de altitude. Distribuição geográfica: Brasil e Guiana Francesa. Distribuição no Brasil: BA (C.J.P. Bastos, dados não publicados) e PA.

7. Cyclolejeunea peruviana (Lehm. \& Lindenb.) A. Evans, Bull. Torrey Bot. Club 31: 196. 1904.

Fig 36-43

Material examinado: BRASIL. Pernambuco: Município de Jaqueira, RPPN Frei Caneca, Serra do 

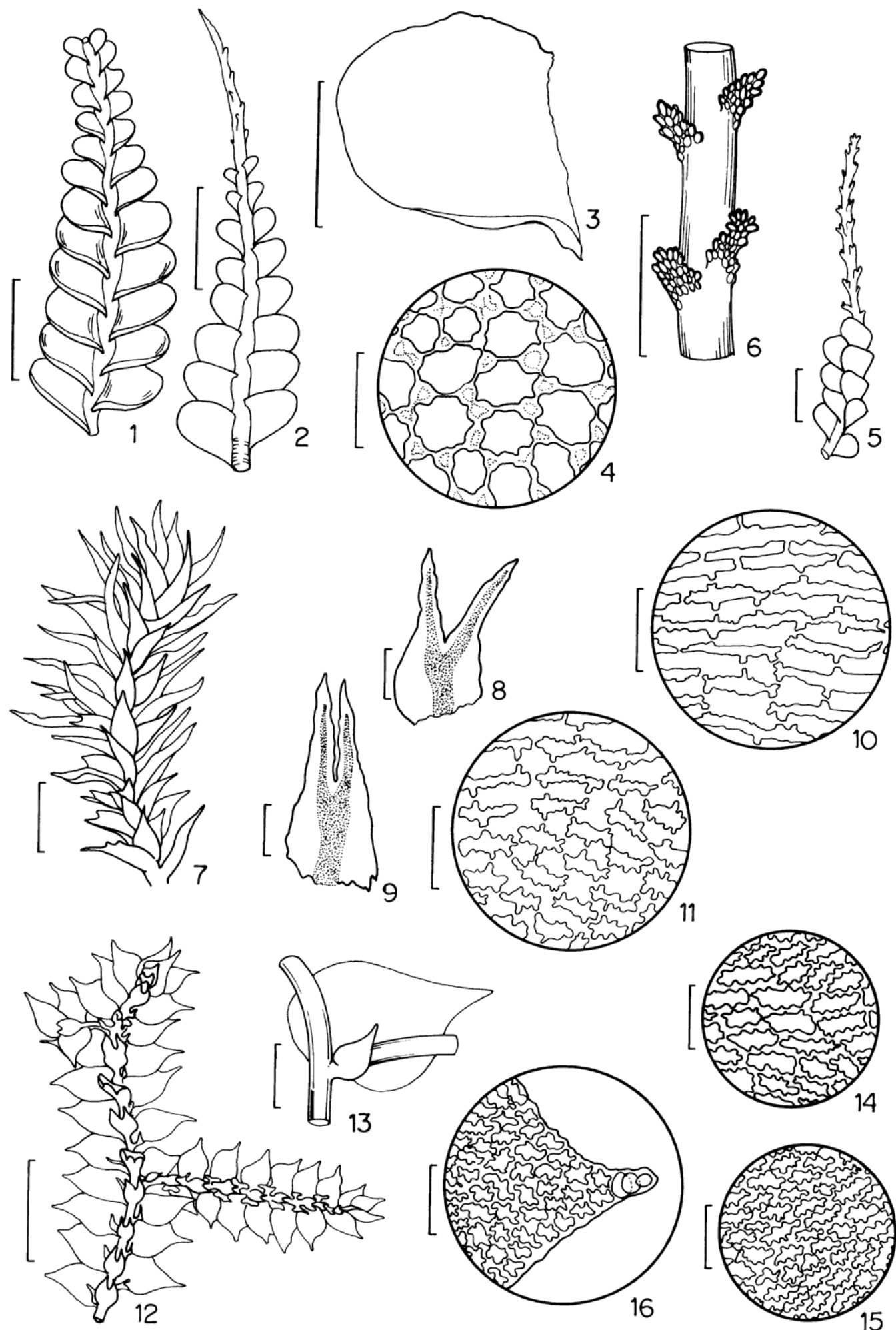

Figuras 1-6. Odontoschisma denudatum (Nees) Dumort. 1. Aspecto geral do gametófito, face dorsal. 2. Aspecto geral do gametófito, face ventral. 3. Filídio. 4. Células medianas do filídio. 5. Ramo flageliforme. 6. Detalhe do ramo flageliforme. Figuras 7-11. Herbertus juniperoideus (Sw.) Grolle. 7. Aspecto geral do gametófito. 8. Filídio. 9. Anfigastro. 10. Células da vita. 11. Células medianas do filídio. Figuras 12-16. Frullania breuteliana Gott. 12. Aspecto geral do gametófito, face ventral. 13. Detalhe do ramo lateral. 14. Células da base

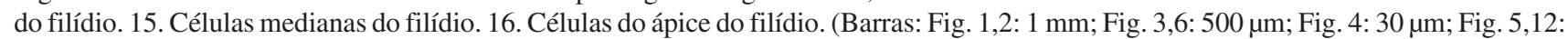

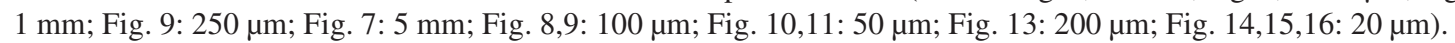



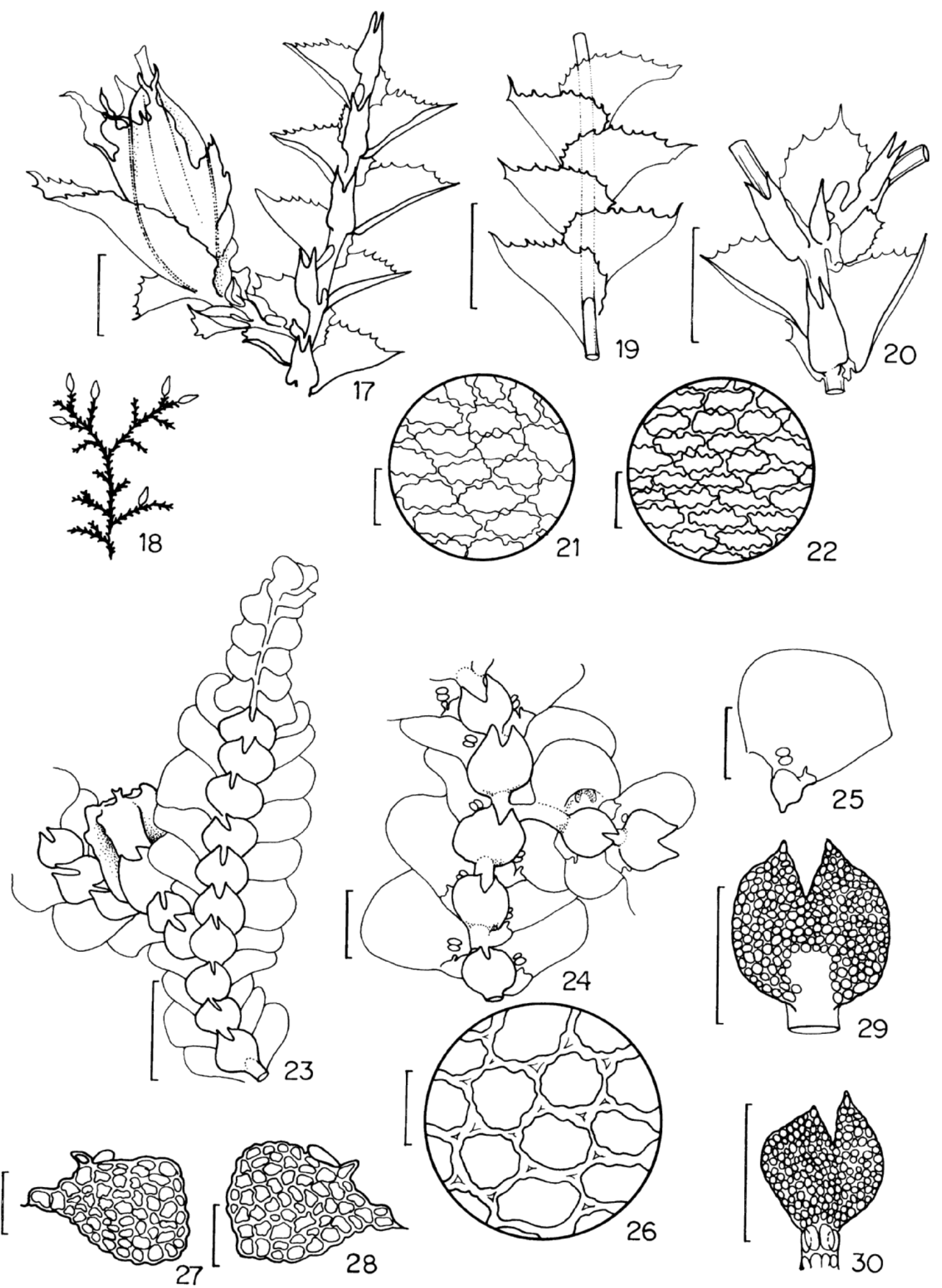

Figuras 17-22. Frullania involuta Hampe ex Steph. 17. Aspecto geral do gametófito, face ventral. 18. Hábito. 19. Aspecto geral do gametófito, face dorsal. 20. Detalhe do gametófito, face ventral. 21. Células da base do filídio. 22. Células medianas do filídio. Figuras 23-30. Ceratolejeunea confusa R.M. Schust. 23. Aspecto geral do gametófito, face ventral. 24. Detalhe do gametófito, face ventral. 25. Filídio. 26. Células medianas do filídio. 27,28. Lóbulos. 29,30. Anfigastros. (Barras: Fig. 17,23: 1 mm; Fig. 19,20,29,30: 200 ㅆm; Fig. 21,22: $20 \mu \mathrm{m}$; Fig. 24,25: $250 \mu \mathrm{m}$; Fig. 26: $25 \mu \mathrm{m}$; Fig. 27: $50 \mu \mathrm{m}$; Fig. 28: $30 \mu \mathrm{m}$ ). 
Quengo, 31/X/2003, sobre folha, L.D.P. Alvarenga (UFP 50888).

Descrição: Bernecker-Lücking (1998)

Comentários: caracteriza-se por filídios com margens denteadas, anfigastros bífidos, com lobos e margens denteadas, e gemas arredondadas. Ramos geminíferos eretos são comuns. Espécie semelhante a C. chitonia (Tayl. ex Lehm.) A. Evans, no entanto, esta última apresenta anfigastros emarginados, de lobos truncados e gemas reniformes. Geralmente encontrada em florestas úmidas, sobre folhas e ocasionalmente em troncos de árvores, entre 0-900 m de altitude. Distribuição geográfica: Neotropical. Distribuição no Brasil: BA e SP.

8. Leptolejeunea maculata (Mitt.) Schiffn., Consp. Hepat. Arch. Ind.: 275. 1898.

Fig. 44-49

Material examinado: BRASIL. Pernambuco: Município de Jaqueira, RPPN Frei Caneca, Serra do Quengo, 31/X/2003, sobre folha, L.D.P. Alvarenga (UFP 50889).

Descrição: Bischler (1969), como L. convexistipa Bischler.

Comentário: caracteriza-se pelos filídios fortemente assimétricos, denteados, de três a seis dentes unicelulares na margem dorsal e dois a quatro dentes na margem ventral, ápice agudo, e 2 a 3 ocelos em fileira. Geralmente encontrada como epífila em florestas úmidas de terras baixas, até $200 \mathrm{~m}$ de altitude. Distribuição geográfica: Pantropical. Distribuição no Brasil: AM e RJ. Novo registro para o Nordeste.

9. Lejeunea cerina (Lehm. \& Lindenb.) Gottsche, Lindenb. \& Nees, Syn. Hepat.: 391. 1845.

Fig. 50-57

Material examinado: BRASIL. Pernambuco: Município de Jaqueira, RPPN Frei Caneca, Serra do Quengo, 25/III/2003, sobre tronco vivo, L.D.P. Alvarenga (UFP 50942); 30/X/2003, sobre tronco vivo, L.D.P. Alvarenga (UFP 50927; UFP 50983); ibid. 31/X/2003, sobre folha, L.D.P. Alvarenga (UFP 50889; UFP 50892); Serra do Espelho, 30/X/2003, sobre folha, L.D.P. Alvarenga (UFP 50883).

Descrição: Gradstein \& Costa (2003).

Comentários: Lejeunea cerina caracteriza-se por apresentar os filídios apiculados, com pequenos lóbulos ovalados, anfigastros grandes, 4 a 7 vezes a largura do caulídio, fortemente auriculados e imbricados, e periantos com cinco quilhas em ramos laterais curtos. Geralmente encontrada sobre troncos de árvores, rochas ou solo, em elevações de 0-2.300 $m$ de altitude. Distribuição geográfica: Neotropical. Distribuição no Brasil: AC, ES, RJ e SP. Novo registro para o Nordeste.

\section{LEPIDOZIACEAE}

10. Lepidozia cupressina (Sw.) Lindenb., in Gottsche et al., Syn. Hepat.: 207. 1845.

Fig. 58-61

Material examinado: BRASIL. Pernambuco: Município de Jaqueira, RPPN Frei Caneca, Serra do Quengo, 31/X/2003, sobre tronco vivo, K.C. Pôrto (UFP 37963).

Descrição: Fulford (1966) e Gradstein \& Costa (2003).

Comentários: caracteriza-se pelos filídios largos, ca. $0,8 \mathrm{~mm}$, côncavos a quase planos, quadrífidos, com cada segmento terminando em uma a duas células. Espécie semelhante a L. brasiliensis Steph., porém essa última apresenta filídios menores (ca. 0,6 mm). Geralmente encontrada em florestas montanas sobre solo, rochas e troncos vivos ou em decomposição, em altitudes de 800-2.400 m. Distribuição geográfica: América Tropical, África e Europa. Distribuição no Brasil: BA, RJ e SP.

\section{METZGERIACEAE}

11. Metzgeria conjugata Lindenb., Acta Soc. Sci. Fenn. 10: 495. 1875.

Fig. 62-65

Material examinado: BRASIL. Pernambuco: Município de Jaqueira, RPPN Frei Caneca, Serra do Espelho, 31/X/2003, sobre folha, L.D.P. Alvarenga (UFP 50883).

Descrição: Costa \& Machado (1992).

Comentários: espécie monóica, muito similar a M. myriopoda Lindenb., quando estéril, porém não apresenta gemas, enquanto $M$. myriopoda tem numerosas gemas marginais. Geralmente encontrada sobre troncos de árvores, ocasionalmente em rochas ou troncos em decomposição, 0-2.000 m de altitude. Distribuição geográfica: Subcosmopolita. Distribuição no Brasil: CE, ES, MG, PR, RJ, RS e SP.

\section{BRYOPHYTA}

\section{CALYMPERACEAE}

12. Leucophanes molleri Müll.-Hal., Flora 69: 285. 1886.

Fig. 66-69 

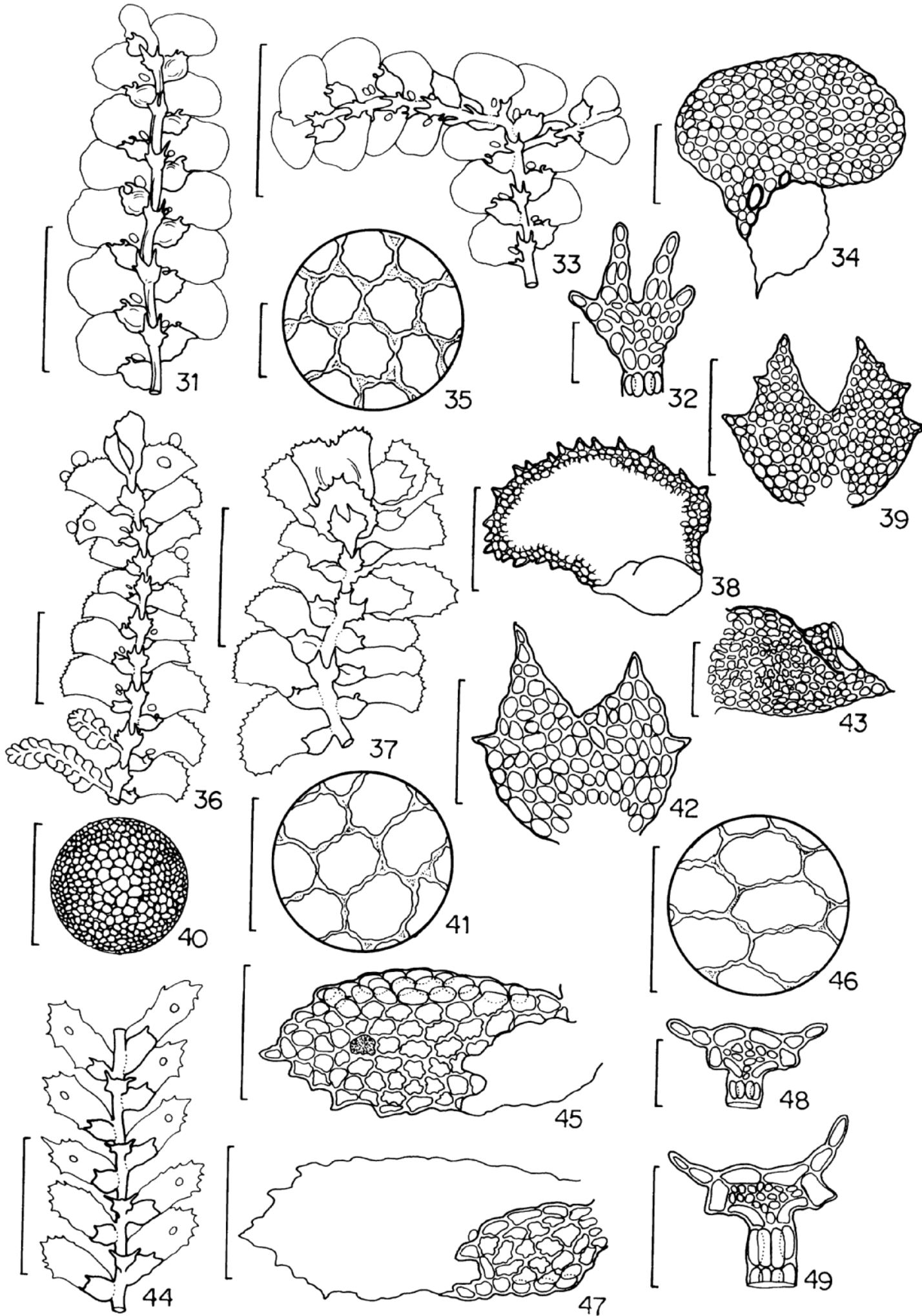

Figuras 31-35. Ceratolejeunea minuta Dauphin. 31. Aspecto geral do gametófito, face ventral. 32. Anfigastro. 33. Detalhe do gametófito, face ventral. 34. Filídio. 35. Células medianas do filídio. Figuras 36-43. Cyclolejeunea peruviana (Lehm. \& Lindenb.) A. Evans. 36 . Aspecto geral do gametófito, face ventral. 37. Detalhe do gametófito com perianto, face ventral. 38. Filídio. 39. Anfigastro. 40. Gema. 41. Células medianas do filídio. 42. Anfigastro. 43. Lóbulo. Figuras 44-49. Leptolejeunea maculata (Mitt.) Schiffn. 44. Aspecto geral do gametófito, face ventral. 45. Filídio. 46. Células medianas do filídio. 47. Filídio. 48,49. Anfigastros. (Barras: Fig. 31,33,44: 0,5 mm; Fig. 34,40,43,49:

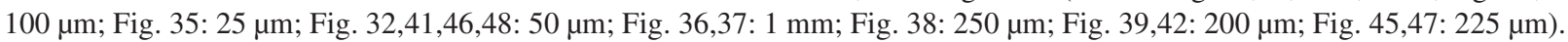



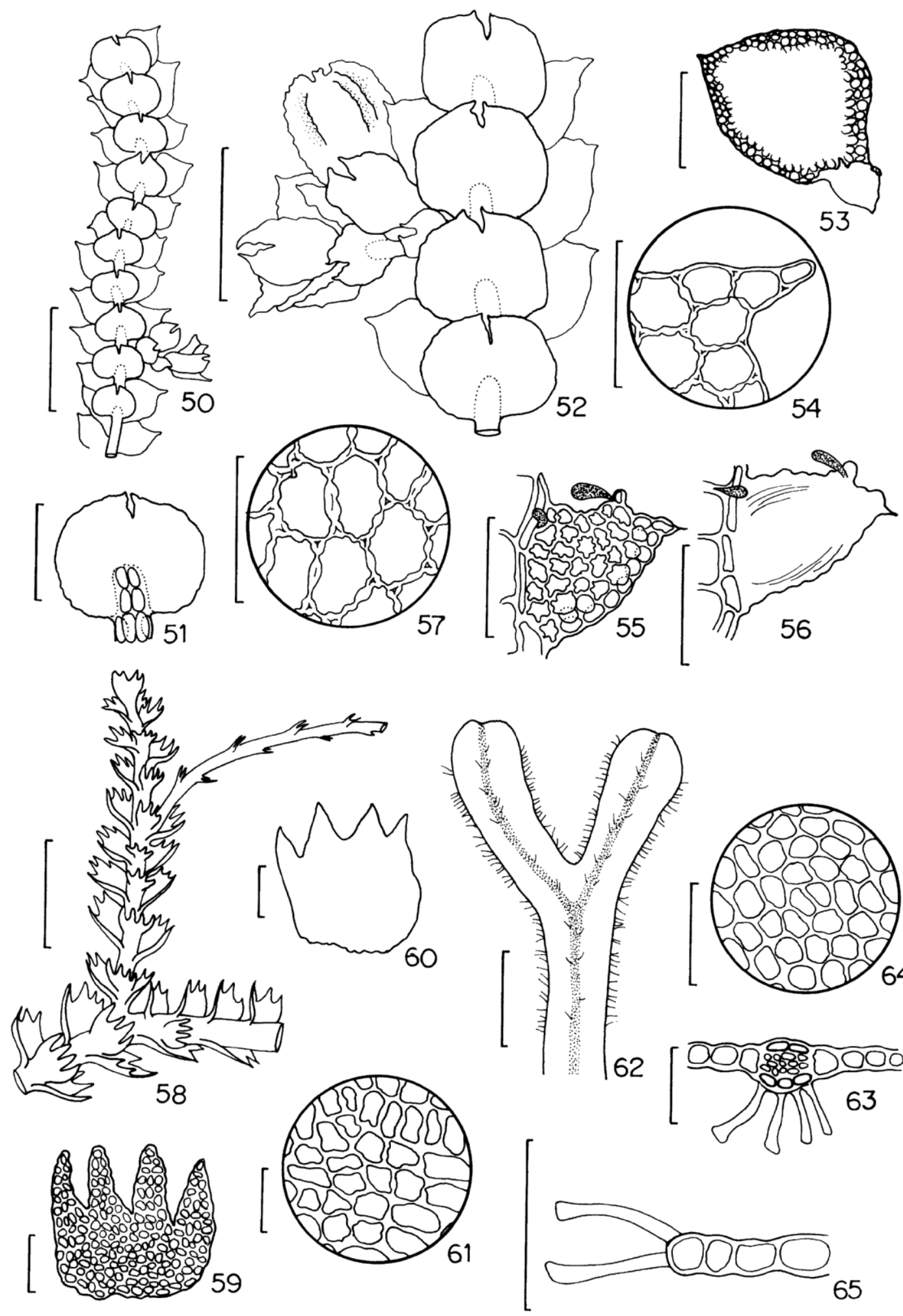

Figuras 50-57. Lejeunea cerina (Lehm. \& Lindenb.) Gottsche, Lindenb. \& Nees. 50. Aspecto geral do gametófito, face ventral. 51. Anfigastro. 52. Detalhe do gametófito com perianto, face ventral. 53. Filídio. 54. Detalhe do ápice do filídio. 55,56. Lóbulos com papila hialina. 57. Células medianas do filídio. Figuras 58-61. Lepidozia cupressina (Sw.) Lindenb. 58. Aspecto geral do gametófito, face ventral. 59. Anfigastro. 60. Filídio. 61. Células medianas do filídio. Figuras 62-65. Metzgeria conjugata Lindenb. 62. Aspecto geral do gametófito, face ventral. 63. Secção transversal do talo. 64. Células medianas do talo. 65. Secção transversal da asa do gametófito. (Barras:

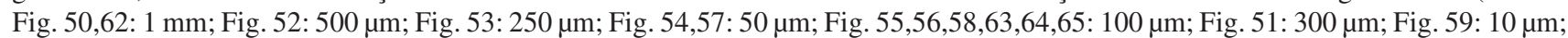
Fig. 60: $20 \mu \mathrm{m}$; Fig. 61:30 $\mu \mathrm{m})$. 
Material examinado: BRASIL. Pernambuco: Município de Jaqueira, RPPN Frei Caneca, Serra do Quengo, 30/X/2003, sobre tronco vivo, L.D.P. Alvarenga (UFP 50927; 50960; 50984; 50986).

Descrição: Allen (1993).

Comentários: caracteriza-se pelos filídios estreitamente lanceolados, 3,0-4,5×0,2-0,4(0,5) $\mathrm{mm}$, flexuosos a eretos, lâmina hialina ocupando 1/2-1/3 de altura no filídio; em secção transversal apresenta uma camada de hialocistos nas faces abaxial e adaxial e uma camada central de clorocistos e quatro fileiras de estereídeos uni- a multiestratosos; costa estreita e células hialinas acima do meio do filídio. Geralmente encontrada como epífita e epíxila em florestas úmidas, do nível do mar até ca. $1.200 \mathrm{~m}$ de altitude. Distribuição geográfica: Afro-Americana. Distribuição no Brasil: AM, PA, RO, RR e SP. Novo registro para o Nordeste.

\section{PTEROBRYACEAE}

13. Calyptothecium duplicatum (Schwaegr.) Broth., in Engler \& Prantl. Nat. Pflanzenfam. 1(3): 839. 1906.

Fig. 70-75

Material examinado: BRASIL. Pernambuco: Município de Jaqueira, RPPN Frei Caneca, Serra do Quengo, 30/X/2003, sobre tronco vivo, L.D.P. Alvarenga (UFP 50917).

Descrição: Buck (1998).

Comentários: Calyptothecium duplicatum caracteriza-se pelo gametófito pinado, com ramos primários prostrados e os secundários eretos, com numerosas pseudoparafílias filamentosas; filídios dos ramos secundários complanados, com costa delgada, atingindo ca. 1/2 da altura da lâmina; células medianas lineares, de paredes espessas e porosas, e as alares fracamente diferenciadas. Buck (1998) menciona que a espécie pode ser confundida com Neckera urnigera Müll. Hal., mas esta ultima é menos robusta e possui costa curta e dupla. Gradstein et al. (2001) comentam que $C$. duplicatum difere de sua congenérica C. planifrons (Renauld \& Paris) Argent pelo fato desta última ser raramente ramificada e apresentar seta curta. Calyptothecium duplicatum é geralmente encontrada como epífita ou rupícula em florestas úmidas de 400-2.000 m de altitude. Distribuição geográfica: Neotropical. Distribuição no Brasil: MG, PR, RJ, RS, SC e SP. Novo registro para o Nordeste.

\section{SEMATOPHYLLACEAE}

14. Sematophyllum adnatum (Michx.) E. Britton, Bryologist 5: 65. 1902.

Fig. 76-81

Material examinado: BRASIL. Pernambuco: Município de Jaqueira, RPPN Frei Caneca, Serra do Quengo, 30/X/2003, sobre tronco vivo, L.D.P. Alvarenga (UFP 50923).

Descrição: Buck (1998).

Comentários: esta espécie é semelhante a S. subpinnatum (Brid.) E. Britton, entretanto apresenta filídios lanceolados e gradualmente acuminados, células apicais pouco diferenciadas e células alares não conspicuamente infladas. Os filídios de $S$. subpinnatum são ovalados a oblongo-ovalados, têm ápice agudo a curto acuminado e células alares grandes e infladas, que podem se estender ao longo de toda a inserção. Encontrada em troncos de árvores e troncos em decomposição, raramente em solo ou rochas, em locais abertos de $0-1.000 \mathrm{~m}$ de altitude. Distribuição geográfica: Afro-Americana. Distribuição no Brasil: AM, BA, DF, ES, MT, PA e RJ.

\section{THUIDIACEAE}

15. Cyrto-hypnum scabrosulum (Mitt.) W.R. Buck \& H.A. Crum, Contr. Univ. Michigan Herb. 17: 67. 1990. Fig. 82-86

Material examinado: BRASIL. Pernambuco: Município de Jaqueira, RPPN Frei Caneca Mata do Fervedouro, 27/III/2003, sobre tronco vivo, L.D.P. Alvarenga (UFP 51055).

Descrição: Buck (1998).

Comentários: caracteriza-se por apresentar os filídios dos ramos secundários incurvados quando secos, parafílias não ramificadas, com duas a cinco células de comprimento e células com duas a cinco papilas sobre o lúmen em ambas as faces. Espécie semelhante a C. schistocalyx (Müll. Hal.) W.R. Buck \& H.A. Crum., no entanto, nos fílídios periqueciais a costa atinge o ápice em $C$. scabrosulum, enquanto em C. schistocalyx restringe-se à base. Geralmente encontrada em florestas mésicas e úmidas de terras baixas, sobre rochas calcárias e troncos em decomposição, entre 0-300 m de altitude. Distribuição geográfica: Neotropical. Distribuição no Brasil: AC, AM, DF, MT, PA, RO e RR. Novo registro para o Nordeste. 

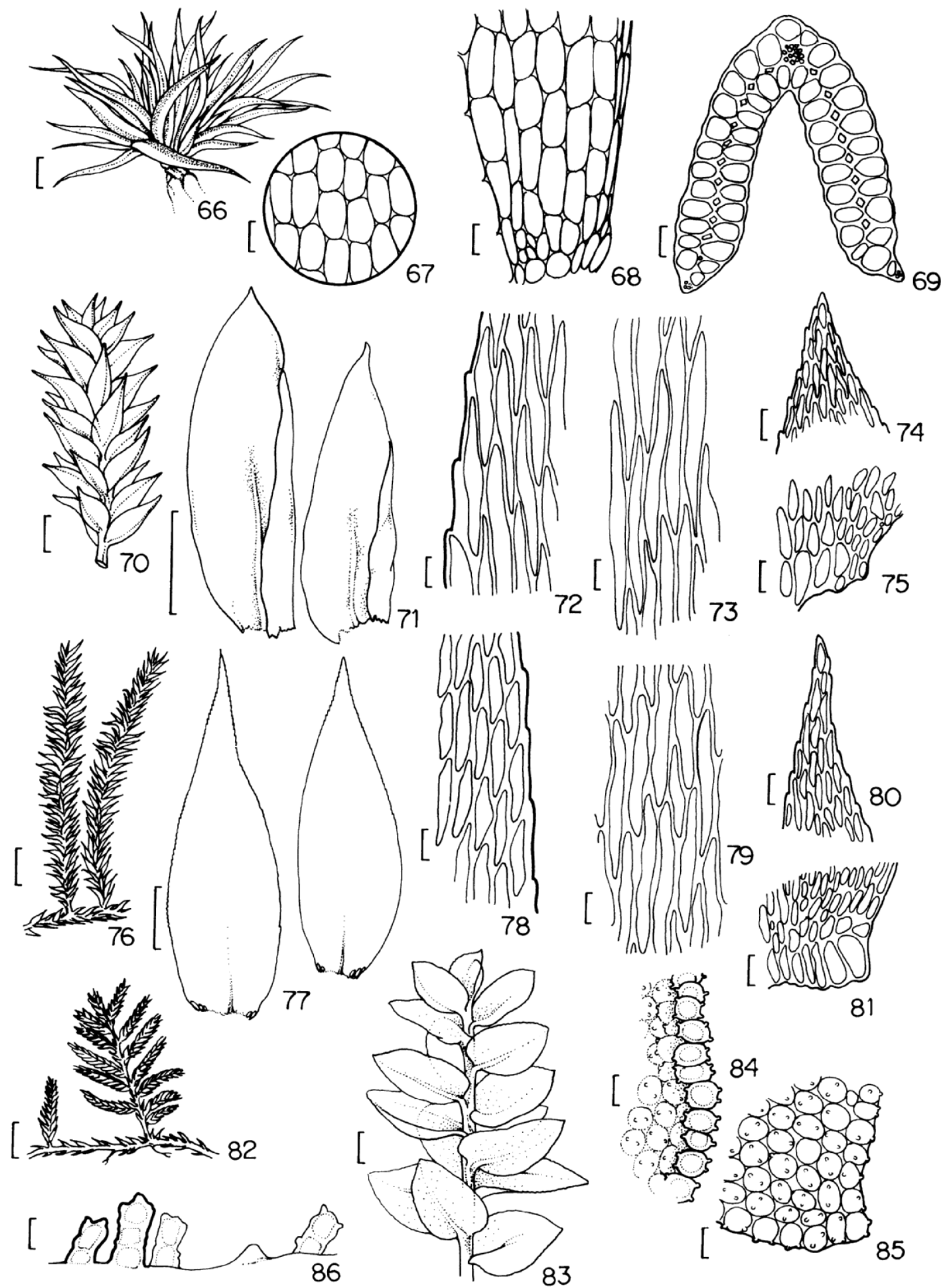

79
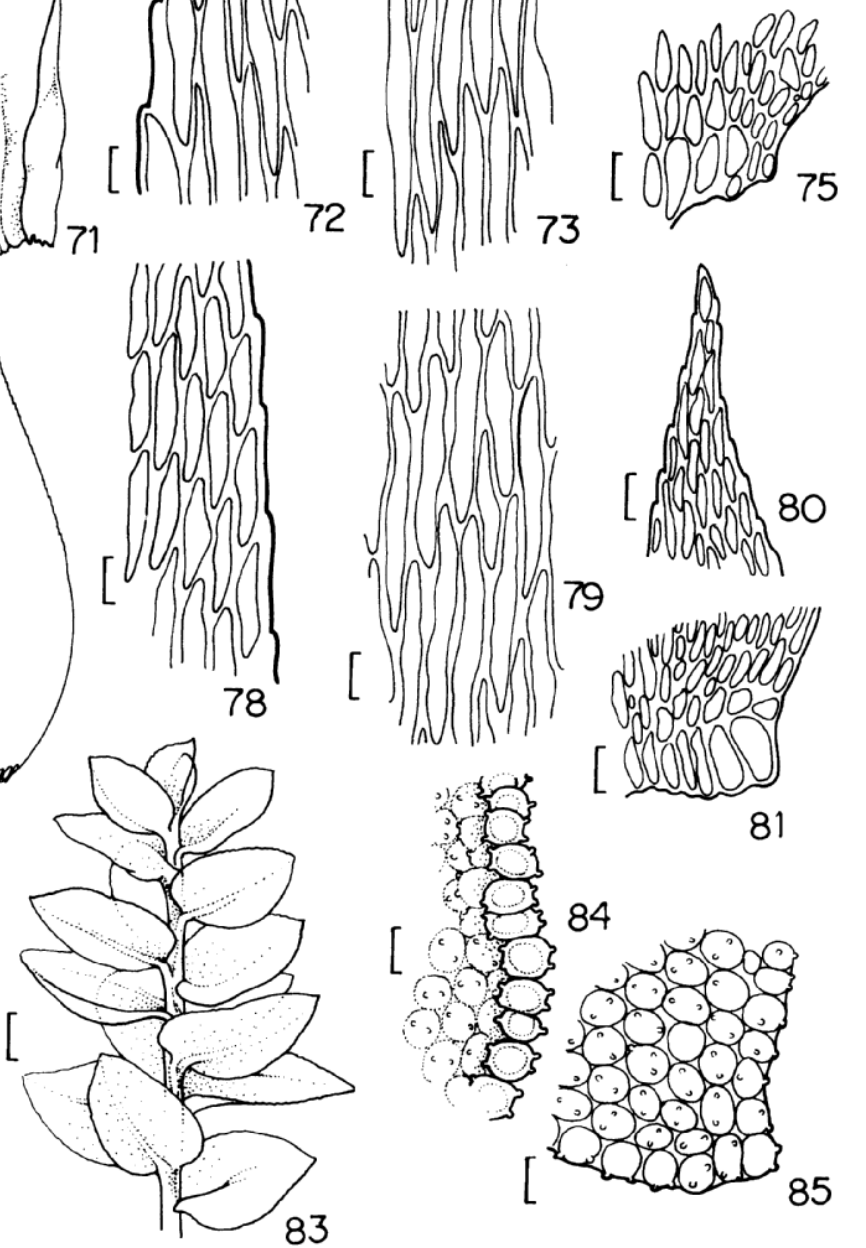

Figuras 66-69. Leucophanes molleri Müll.-Hal. 66. Aspecto geral do gametófito. 67. Células medianas do filídio. 68. Células da base do filídio. 69. Secção transversal da base do filídio. Figuras 70-75. Calyptothecium duplicatum (Schwaegr.) Broth. 70. Aspecto geral do gametófito. 71. Filídios. 72. Células da margem do filídio. 73. Células medianas do filídio. 74. Detalhe do ápice do filídio. 75 . Detalhe da base do filídio. Figuras 76-81. Sematophyllum adnatum (Michx.) E. Britton. 76. Aspecto geral do gametófito. 77. Filídios. 78. Células da margem do filídio. 79. Células medianas do filídio. 80. Detalhe do ápice do filídio. 81. Detalhe da base do filídio. Figuras 82-86. Cyrto-hypnum scabrosulum (Mitt.) W.R. Buck \& H.A. Crum. 82. Aspecto geral do gametófito. 83. Detalhe do gametófito. 84. Células da margem do filídio, com papilas. 85. Células medianas do filídio. 86. Parafília. (Barras: Fig. 66,70,76,82: 1 mm; Fig. 67,68,72,73,78,79,84,85,86: $10 \mu \mathrm{m}$; Fig. 69,74,75,77,80,81: $20 \mu \mathrm{m}$; Fig. 71: $500 \mu \mathrm{m}$. Fig. 83: $100 \mu \mathrm{m}$ ). 


\section{Agradecimentos}

As autoras agradecem às especialistas Dra. Denise Pinheiro Costa, do Jardim Botânico do Rio de Janeiro, Dra. Helena Reiner-Drehwald da Universidade de Göttingen, Alemanha e Dra. Olga Yano do Instituto de Botânica de São Paulo, pelo auxílio na identificação de algumas amostras e ao apoio do Projeto da Conservação e Utilização Sustentável da Diversidade Biológica Brasileira - PROBIO/ CNPq/ MMA.

\section{Referências bibliográficas}

Allen, N.S. 1993. A Revision of the Pantropical Moss Genus Leucophanes Brid. Bryophytorum Bibliotheca 46: 1-281.

Andrade, G.O. \& Lins, R.C. 1984. Pirapama: um Estudo Geográfico e Histórico. Recife, Massangana (Estudos e Pesquisas, 31).

Bernecker-Lücking, A. 1998. The genus Cyclolejeunea A. Evans in Costa Rica. Phyton 38: 175-193.

Bischler, P.H. 1969. Le genre Leptolejeunea (Spruce) Steph. en Amérique. Nova Hedwigia 17: 265-272.

Buck, W.R. 1998. Pleurocarpous Mosses of the West Indies. Memoirs of The New York Botanical Garden 1: 1-401.

Câmara, P.E.A.S. \& Vital, D.M. 2004. Briófitas do Municipio de Poconé, Pantanal de Mato Grosso, MT, Brasil. Acta Botanica Brasilica 18(4): 881-886.

Câmara, P.E.A.S. \& Leite, R.N. 2005. Bryophytes from Jalapão, state of Tocantins, northern Brazil. Tropical Bryology 26: 23-29.

Câmara, P.E.A.S.; Oliveira, J.R.P.M. \& Santiago, M.M.M. 2005. A Checklist of the bryophytes of Distrito Federal (Brasília, Brazil). Tropical Bryology 26: 133-140.

Costa, D.P. \& Machado, R.D. 1992. Morphology of Metzgeria conjugata Lindb. (Metzgeriales, Hepaticopsida). Tropical Bryology 6: 65-69.

Costa, D.P.; Imbassahy, C.A.A. \& Silva, V.P.A.V. 2005. Checklist and distribution of mosses, liverworts and hornworts of Rio de Janeiro state, Brazil. The Journal of the Hattori Botanical Laboratory 98: 259-298.

Crandall-Stotler, B. \& Stotler, R.E. 2000. Morphology and classification of the Marchantiophyta. Pp. 21-70. In: A.J. Shaw \& B. Goffinet (orgs.). Bryophyte Biology. Cambridge University Press, Cambridge.

Dauphin, G. 2003. Ceratolejeunea. Flora Neotropica, monograph 90(27): 1-86.

Fulford, M.H. 1963. Manual of the leafy Hepaticae of Latin America - Part I. Memoirs of The New York Botanical Garden 11(1): 1-172.

Fulford, M.H. 1966. Manual of the leafy Hepaticae of Latin America - Part II. Memoirs of The New York Botanical Garden 11(2): 173-276.

Germano, S.R \& Pôrto, K.C. 1996. Floristic survey of epixylic bryophytes of an area remnant of the Atlantic Forest (Timbaúba - PE, Brazil) 1. Hepaticopsida (except Lejeuneaceae) \& Bryopsida. Tropical Bryology 12: 21-28.
Germano, S.R. \& Pôrto, K.C. 2004. Novos Registros de Briófitas para Pernambuco, Brasil. Acta Botanica Brasilica 18(2): 343-350.

Germano, S.R. \& Pôrto, K.C. 2005. A Bryophyte Checklist of the Ecological Reserve of Gurjaú, Pernambuco, Brazil. Tropical Bryology 26: 1-12.

Goffinet, B. \& Buck, W.R. 2004. Sistematics of the Bryophyta (Mosses): from molecules to a revised classification. Pp: 205-239. In: B. Goffinet, V. Hollowell \& R. Magill (eds.). Molecular Systematics of Bryophytes. St. Louis, Missouri Botanical Garden.

Gradstein, S.R. \& Pócs, T. 1989. Bryophytes. Pp. 311-325 In: H. Lieth \& M.J.A. Werger (eds.). Tropical Rain Forest Ecossystems. Elsevier Science Publishers B.V., Amsterdam.

Gradstein, S.R. \& Costa, D.P. 2003. The Hepaticae and Anthocerotae of Brazil. Memoirs of The New York Botanical Garden 87: 1-318.

Gradstein, S.R.; Churchill, S.P. \& Allen, N.S. 2001. Guide to the Bryophytes of Tropical America. Memoirs of The New York Botanical Garden 86: 1-577.

Harley, R.M. 1995. Flora of the Pico das Almas, Chapada Diamantina - Bahia, Brazil. Royal Botanic Gardens.

Kron, K.A. 1988. Taxonomic Study of Venezuelan Members of Frullania Raddi subg. Meteoriopsis Spruce. The Journal of the Hattori Botanical Laboratory 64 : 347-358.

Lisboa, R.C.L. \& Lima, M.J.L.L. 1997. Leucophanaceae, nova família de Bryophyta para o Pará, Brasil. Acta Botanica Brasilica 11(1): 79-85.

Pôrto, K.C. 1990. Bryoflores d'une forêt de plaine et d'une forêt d'altitude moyenne dans l'État de Pernambuco (Brésil): Analyse floristique. Cryptogamie, Bryologie Lichénologie 11(2): 109-161.

Pôrto, K.C. 1996. Briófitas. Pp. 97-109. In: E.V.S.B. Sampaio; S.J. Mayo \& M.R.V. Barbosa (eds.). Pesquisa Botânica Nordestina: Progresso e Perspectivas. Recife, Sociedade Botânica do Brasil, Seção Regional Pernambuco.

Pôrto, K.C. \& Germano, S.R. 2002. Biodiversidade e importância das briófitas na conservação dos ecossistemas naturais de Pernambuco. Pp: 125-152. In: M. Tabarelli \& J.M.C. Silva (orgs.). Diagnóstico da biodiversidade de Pernambuco. Recife, Massangana.

Pôrto, K.C.; Germano, S.R. \& Oliveira, S.M. 2000. New records of bryophytes Pernambuco State, Brazil. Tropical Bryology 18: 107-114.

Pôrto, K.C.; Belo, M.M.L.; Fonseca, E.R. \& Silva E.C. 1993. Brioflora da Reserva do Gurjaú (Cabo - PE). Biologica brasilica 5(1/2): 27-42.

Pôrto, K.C.; Gradstein, S.R., Yano, O.; Germano, S.R. \& Costa, D.P. 1999. New and interesting records of Brazilian bryophytes. Tropical Bryology 17: 19-45.

Reese, W.D. 1993. Calymperaceae. Flora Neotropica, monograph 50: 1-102.

Sharp, A.J.; Crum, H. \& Eckel, P.M. 1994. The moss flora of Mexico. Memoirs of The New York Botanical Garden 69(1-2): 1-1113. 
Siqueira Filho, J.A. \& Leme, E.M.C. 2000. Suplemento: Neoregelia Subgênero Longipetalopsis. Pp. 231-237. In: E.M.C. Leme (ed.). Nidularium - Bromélias da Mata Atlântica/Bromeliads of the Atlantic Forest. Rio de Janeiro, Sextante.

Stotler, R.E. 1970. The Genus Frullania in Latin America. Nova Hedwigia 18: 397-555.

Tabarelli, M. \& Silva, J.M.C. 2002. Introdução. Pp. 9-12. In: M. Tabarelli \& J.M.C. Silva (eds.). Diagnóstico da biodiversidade de Pernambuco. Recife, Massangana.

Valente, E.B. \& Pôrto, K.C. 2006. Hepáticas (Marchantiophyta) de um fragmento de Mata Atlântica na Serra de Jibóia, Município de Santa Teresinha, BA, Brasil. Acta Botanica Brasilica 20(2):433-441.

Van Reenen, G.B.A. 1982. Studies on Colombian Cryptogams XII. High Andean species of Herbertus S.F. Gray (Hepaticae). Lindbergia 8: 110-120.

Veloso, H.P.; Filho, A.L.R.R. \& Lima, J.C.A. 1991. Classificação da vegetação brasileira, adaptada a um sistema universal. IBGE, Departamento de Recursos Naturais e Estudos Ambientais, Rio de Janeiro.
Visnadi, S.R. 2004. Distribuição da brioflora em diferentes fisionomias de cerrado da Reserva Biológica e Estação Experimental de Mogi-Guaçu, SP, Brasil. Acta Botanica Brasilica 18(4):965-973.

Yano, O. 1981. A checklist of Brazilian mosses. The Journal of the Hattori Botanical Laboratory 50: 279-456.

Yano, O. 1984. Checklist of Brazilian liverworts and hornworts. The Journal of the Hattori Botanical Laboratory 56: 481-548.

Yano, O. 1989. An additional checklist of Brazilian bryophytes. The Journal of the Hattori Botanical Laboratory 66: 371-434.

Yano, O. 1995. A new additional annotated checklist of Brazilian bryophytes. The Journal of the Hattori Botanical Laboratory 78: 137-182.

Yano, O. 2004. Novas ocorrências de briófitas para vários estados do Brasil. Acta Amazonica 34(4): 559- 576.

Yano, O. 2006. Novas adições ao catálogo de Briófitas brasileiros. Boletim do Instituto de Botânica 17: 1-142.

Yano, O. \& Câmara, P.E.A.S. 2004. Briófitas de Manaus, Amazonas, Brasil. Acta Amazonica 34(3): 445- 457.

Yano, O. \& Pôrto, K.C. 2006. Diversidade das briófitas das matas serranas do Ceará, Brasil. Hoehnea 33(1): 7-39. 